\title{
Approaching Agency in Intra-Activities
}

\author{
Liv Torunn Grindheim
}

\begin{abstract}
The 1989 United Nations Convention on the Rights of the Child that legalise children's right to express their views, underlines that children have relevant perspectives and agency. This approach has been an enormous gift to the field of social childhood studies. In our contemporary, transforming, and rapidly changing society, the time has come to move forward with this concept and to challenge the dichotomy between agency and structure. Supporters of the 'material turn' claim that their way of thinking makes room for the expansion of agency as an enactment, something that someone or something has, toward agency as 'doing'/'being' in its intra-activity. Intra-action reformulates the traditional notion of causality and opens up a relatively large space for material-discursive forms of agency. To understand and take into account this larger space for material-discursive forms of agency, an outline of methods for tracing the actors involved in intra-activities is needed. The chapter is therefore structured around the question: How can emerging actors be traced in an intra-activity? Thus, discursive formation due to the materials involved and hegemonic ideas can be depicted. The actors are traced in an activity involving Polydron, a building toy. The research method has a participatory and explorative design, and the relevant actors emerge throughout the research process. Polydron, children, teachers, families, the economy, play, learning, and the position of mathematics in education: these all emerge as actors. Accordingly, a range of actors that intra-act in the presented activity is depicted through networks of connection and disconnection, and paves the way for a continuum of practices to emerge. Thus, the space for agency between actors and structures can be recognised and widened.
\end{abstract}

\section{Keywords}

early childhood education - agency - exploration - intra-activity - actors

(C) LIV TORUNN GRINDHEIM, 2021 | DOI: 10.1163/9789004445666_011 
The UN Convention on the Rights of the Child that legalise children's right to express their views (United Nations, 1989, art. 12), underlines that children have relevant perspectives and agency. Approaching children's agency has been an enormous gift to the field of social childhood studies (James, 2009). Ethnographic and anthropological research designs studying children in their everyday life have revealed how children are actors and constructors of their experiences and their everyday life. Interpreting agency in this way points to interesting research that depicts the necessity of understanding children's development culturally (Nsamenang, 2008, p. 219); it reveals how agency can be recognised as more than spoken language (Colegrove \& Adair, 2014, p. 131); and it claims that children's agency should be given greater acceptance, for example, in ways of assessing children (Buzzelli, 2015, p. 210). Despite these valuable contributions obtained by creating childhood as a phenomenon within sociological discourse, Prout (2011) argues that the increasing complexity and ambiguity of childhood as a contemporary, destabilised phenomenon are not confronted, since the space for 'childhood' was created largely by the terms of modernist sociology. Prout (2011) claims that one aspect of this problem is apparent in the reproduction of the dichotomised oppositions between children's agency and childhood as a social construct within the sociology of childhood - the same goes for such dichotomies as nature and culture, and children as being and becoming.

As a way of dealing with these challenging dichotomies, Prout (2011) points to the 'excluded middle' as a way of meeting the increasing complexity and ambiguity of childhood as a contemporary, destabilised phenomenon. He points to Latour's (1993) 'actor-network theory' and to the 'rhizome' metaphor found in Deleuze and Guattari (1988). In these approaches, attention is drawn to the materials and practices from which an endless stream of new phenomena, including distinctions and dichotomies, are generated and emerge. In line with emphasising the excluded middle, I call for expanding the understanding of agency by involving more than humans and language by outlining material-discursive elements to discover formation and agency, inspired by Latour (2008) and Barad (2003). Thereby, I take departure from what is often referred to as the 'material turn'. The material turn indicates that more than humans (i.e. artifacts, architecture) are to be taken into consideration when exploring agency.

Supporters of the material turn claim that their way of thinking makes room for the expansion of agency as an enactment, something that someone or something has, toward agency as 'doing'/'being' in its intra-activity (Barad, 
2003, p. 827). Since intra-action reformulates the traditional notion of causality and opens up a space, it creates a relatively large space for material-discursive forms of agency. To understand and take into account this larger space for material-discursive forms for agency, an outline of methods for tracing actors involved in an intra-activity is needed. The chapter is therefore structured around the question: How can emerging actors be traced in an intra-activity? Thereby, discursive formation due to the materials involved and hegemonic ideas can be depicted. My overall aim is to broaden the possibility for agency to emerge in networks/ensembles in early childhood education (ECE). My contribution could pave the way for teachers and researchers to take into consideration that there will always be several actors involved when a child comes forward as competent or incompetent, not meeting the standards of what is expected for a child, or not meeting the expected aims for activities in ECE. Pointing to several actors in a network provides a wider repertoire for what to challenge or 'mend', rather than fixing an individual child's ability to act.

The involved actors are traced from an activity where children are playing with a building toy called Polydron in light of my understanding of Barad's (2003) outlines of intra-activity (intra-action) and agency, and Latour's (2008) outlines of actor-network theory. The research method has a participatory and explorative design in which relevant material for analysis emerges throughout the research process. Polydron, children, teachers, families, economic, play, learning, and the position of mathematics in education: these all emerge as actors that intra-act in the presented activity and in the research process. Thus, a range of actors that intra-act are depicted and, therefore, the space for agency in the network of actors can be recognised and widened.

Theoretical Concepts

There seems to be an emerging interest for reconceptualising agency in ECE (Esser et al., 2016). Spyrou (2018) states that the need for reconceptualisation emerges from the apparent 'notion of agency' that "as property of self is theoretically limiting for the field. An understanding of agency which rests in the knowledgeable, self-reflexive, independent, and autonomous individual child finds its conceptual limits in light of social life's relationality, connectedness, and interdependence" (p. 147). Several researchers contribute in this area (e.g. Bordonaro \& Payne, 2012; Lee, 2001; Leonard, 2016; Valentine, 2011; Mizen \& Ofosu-Kusi, 2013; Payne, 2012). As several authoritative researchers in early childhood research have done, I turn to Latour (2005) and Barad (2003, 
p. 2007) when trying to capture the actors in a network that are emerging from a specific activity in ECE.

There is an academic expectation to carefully explain newer ontologies and to show weaknesses with the former ontologies - which, in my case, is the sociology of childhood - and how and who has challenged these approaches, and their suggestions for how to meet these weaknesses. This expectation serves as an explanation for the long and detailed theoretic parts in the presentation of posthumanistic research. In contract to this expectation and practice, I simply and briefly point to the research field. Therefore, the rest of the theoretical part of this article is limited to presenting concepts that have room for unpredictability and instability and that have become relevant for how I traced the actors in an intra-activity that involved exploration. These concepts are exploration, intra-activity, actors and agency.

Exploration: Materials is emphasised in several ontological approaches like phenomenology, semiotics, and cultural-historical theories. In these approaches, the humanistic subjects are most often presented as related to materiality and to the world without being a part of it. Materials are viewed as tools for the conscious, rational humanistic subject (Hultman \& Lenz Taguchi, 2010, p. 539). According to Sandvik (2015), humanistic understanding of the subject leaves material-discursive elements such as non-human materials (e.g., room, furniture, nature, toys, etc.) in the shadows. Therefore, post humanistic approaches aim to challenge the humanistic approach that is taken for granted, whereby language and ways of thinking are presented as the main ways to understand and learn. It is claimed that new insight into agency can be obtained by taking interest in materials.

From the material approach, the importance of understanding everyday practices as open processes and the need to let go of control have been revealed as well as the benefits of understanding pedagogical practices as something that is coming into present (Sandvik, 2015), as performativity (Barad, 2003; Srinivasan, 2018) or as flight pathways (Myhre, Myrvold, Joramo, \& Thoresen, 2017). In addition, the advantage of improvisation is underlined to balance the known and the unknown, freedom and structure, and to improve practices and distribute power (Leirpoll, 2015). There is an outspoken aim to open up to complexity, contradictions, and disruptions (Kummen, 2014). Pedagogical practices are characterised by concepts such as 'letting go of control,' 'coming into present,' 'improvisation,' and 'performativity'. I use the concept of exploration to conceptualise emerging pedagogical practices that open up to the known and the unknown, freedom and structure, complexity, contradictions and disruptions. 
Intra-activity: Researchers that place themselves in the material turn have depicted insight in intra-active processes among actors (Barad, 2003; Latour, 2008). Barad (2003, p. 810) calls it "agential realism". In this approach, materials, humans, discourses, and context are viewed as intra-active actors. Hence, for example, materials and humans are more than interrelated. Interrelation indicates that there are limits between those that are involved in an activity. In contrast, intra-active processes indicates that it is impossible to know where one starts and the other one ends; in an ongoing situated practice, all actors are intra-related. According to Barad (2003, p. 802), we need to move toward alternatives to representationalism and "shift the focus from questions of correspondence between descriptions and reality to matters of practices/doing/ actions". I therefore aim to look for intra-activity in an ongoing practice.

Actors: The actor-network theory (ANT) aims to destabilise the subject and thereby allows the consideration of both humans and non-humans as participants in practice (Latour, 2005). According to Lafton (2015), the idea of how human agency is habitually assumed can therefore be reconsidered, and this allows recognition of the forces working between humans and non-humans within a network. According to Latour (2005), an actor can be anything that modifies other actors through a series of actions. An actor makes others act. The action is of main interest, and it will often differ from what was expected. The act is intra-woven in a network of actors, which is not stable and represents a source for insecurity. To trace the actors, I look for what can be seen as destabilising the practice at the present moment. It is not the same as explaining why things happen; it is done with the objective of mapping some of the networks of actors that are woven together.

Agency: The traditional understanding of causality is often outlined from a one-dimensional understanding of someone who acts and then this act leads to a change. Therefore, the ones who act are the ones who realise the action, and they possess/have agency. In contrast to this understanding, Barad (2003) outlines that:

agency is about the possibilities and accountability entailed in reconfiguring material-discursive apparatuses of bodily productions, including the boundary articulations and exclusions that are marked by those practices in the enactment of a causal structure. Particular possibilities for acting exist at every moment, and these changing possibilities entail a responsibility to intervene in the world's becoming, to contest and rework what matters and what is excluded from mattering. (p. 827)

Barad (2003, p. 826) describes intra-activities as providing the conditions for an open future. Therefore, intra-actions are constraining but not determining, 
and neither a matter of strict determinism nor unconstrained freedom. Since intra-action reformulates the traditional notion of causality and opens up a space, it opens up a relatively large space for material-discursive forms of agency (Barad, 2003, p. 826). If several actors are involved in the act, then the act will not be fully known beforehand. The intentional human loses control. I find interest in identifying some of the actors that constitute the act, even if they are changing all the time. A network of actors makes a larger room for agency, since the activity does not emerge only from the effort of what the conscious human intended to do, but rather it starts a new beginning. I therefore look for agency as something that emerges among actors when a larger room for a variety of activities and ways of understanding is depicted.

The experiences that form the basis for my analysis come from a study done in collaboration with teachers and children at an ECE institution in Norway from April 2016 to August 2017. The institution is located in an urban area on the west coast of Norway. During the period of this research, sixty-three children from 1 to 6 years of age were attending the institution. They were divided into four age-specific groups. The staff comprised seven teachers and included the manager and an extra teacher, who took care of the children with special needs, and nine assistants.

Five teachers at this ECE institution made videotapes to illustrate children's activities that they found to be of special interest and value. I visited their institution to pick up the videos and interview the teachers who recorded the activities, meeting one teacher at a time as well as the children in the particular video(s). I visited the institution eleven times, spending between 2 and 4 hours to do the interviews. Altogether, I obtained thirteen videotapes of activities that ranged in length from 1:11 minutes to 10 minutes, and all were followed by comments from the teachers who made the recordings. Seven videos also included comments from the involved children. Although the videos contained activities that took place over the period of one year and involved different teachers, children, activities, and places, they were all from the same institution.

The Norwegian Centre for Research Data approved the project. The teachers who made the recordings signed an agreement form as data processors; all the staff and the parents of the children who were recorded gave their written informed consent to participate in the study and they had the opportunity to withdraw from the study at any time. In addition, the involved children had the opportunity to withdraw from being recorded or watching the video. 
Following my first analysis, which evoked more questions about the teachers' values and motives for the activities they found of specific value and interest, their opinions about play, and the conditions and demands they meet in their daily practices, I did a group interview (about go minutes) with four of the five teachers who had made the videotapes. In addition, I participated in two staff meetings (1 hour each): the first to introduce and discuss my aims and research interest; the second, to present and discuss my findings.

This participatory design is close to an ethnographical approach (Hammersley \& Atkinson, 2007), and offered me, as a researcher, an unfamiliar position that could broaden the variety of topics or objects of research, topics or objects that the researcher would not be aware of in the first place, such as materiality. My awareness of materiality stemmed from an interview with one of the teachers. In the activities she had chosen to videotape, the children's play seems to be strongly influenced by the playthings. Most of the toys I saw were familiar to me, but in one of the videos, there was a toy that was new to me, and that aroused my curiosity. The toy was called Polydron, and asking about it generated even more curiosity. It seems to be very popular with both children and teachers. The awareness of this material made me contact a sales representative from a company that promotes and sells toys to ECE institutions in order to obtain more information about Polydron and about what kinds of toys are most popular for purchase by ECE institutions. This expanding of materials for analysis, through openness for what might emerge in research, is also in line with my engagement in exploration and which forms a basis for both the research and the content of my research. This is in line with Jackson's (2013) outlines of posthumanist data analysis, and it is my attempt to locate agency as an entanglement of constitutive human and non-human elements. The entanglement makes what Pikering (1993) conceptualises as the 'mangle', where both non-humans and humans are constantly coming into being, fading away, moving around, and changing places with one another (Pickering, 1993, p. 563). The aim is to avoid the "trap of representation of a stable 'real" (Jackson, 2013, p. 743). Thus, agency is not located in human intention but in a mangled or emerging practice. This constant emerging practices and actors are impossible to capture, since they are constantly changing and moving. That means that the actors that I trace through my analysis are not stable representations; it is a 'frozen' moment that indicates an awareness for space for agency in an evolving network of actors. The frozen moment provides insight into room for agency that comprises a range of actors that, despite their shifting and emerging positions, are involved and can be challenged - actors that might be left in the shadows if we were to leave out all actors other than humans. 
My analysis to trace emerging actors in an intra-activity involving children and material/toys begins with an activity that was recorded in a video (1:23 minutes) of children playing with Polydron, followed by an interview with their teacher (about 1 hour) to investigate why this recorded play was of specific interest for the teacher. In addition, the material in my analysis also includes comments from the children in the video in dialogue with their teacher and the researcher, the group interview with the teachers in my cooperating ECE institution, and an interview with a sales representative from a company that promotes and sells toys to ECE institutions, and descriptions of the material (Polydron) from various websites.

To trace the emerging actors in the intra-activity involving children and Polydron, I start by presenting the videotape that aroused my interest in the first place. The next steps are in line with the emergence of several actors to inform my research question: the surprising new material, what was made with the material, the teachers' and the children's comments, the parents' interest, the understanding of good play, the history and the ontological meaning of the concept of polydron, the position of mathematics in education, structural learning, political interest in ECE, economy, and profit.

\subsection{The Exploring Activity and Comments about It}

Drawing on the emphasis on activities in the material turn, I start by presenting the activity in the video:

The activity is performed on and around a table. On the table there is a play material called Polydron that woke my interest. In spite of my common visits in ECE institutions - bot as a researcher and as a teacher for ECE teacher students - this toy was unknown to me. At this video three boys are eagerly involved playing with Polydron. They are making a garage for cars. First, they make a one-dimensional road of squareshaped Polydron and place many cars in a line upon it. Then they extend the road and carefully wrap the cars in the connected Polydron pieces. It seems to be a challenge to know how many Polydron pieces are needed to cover the cars and how to connect the pieces of Polydron in 'open air'. The first time in the video, they do not succeed. The pieces of Polydron fall apart and the cars fall off the road. "No problem", one of the boys said, 
placing the car upon the Polydron again, putting the pieces of Polydron together again, and carefully covering the cars with Polydron, using both hands. He had to place the two ends of the so far one-dimensional connected Polydron on the cars, to find a grip for 'clicking' the magnetic Polydron together and thereby make a roof and a garage, a three-dimensional building. "This is a big one", he commented, and he asked the teacher to take a photo of it for their parents. On the table where the activity was taking place, there was already a garage of the same kind. It was even longer. That obvious proof for their ability to make such a garage was thereby present, and further explained the boy's confidence that the breakdown of their garage was not a problem.

In the interview with the teacher who recorded the video, we started by talking about this toy, Polydron. The teacher told me that "Polydron can be used in multiple ways - and in unexpected ways. It is popular with both girls and boys. The bricks are used to make crowns for princesses, garages, balls, and so on". She recorded this video because, as she says,

Polydron was recently purchased for my kindergarten, it is popular with the children, and they play with it daily. The boys are 3 years of age and often play together, and I see them as equals when playing together. I find this activity to be good play. They had been engaged in the activity for a while before I started to record their play.

The children in the video had a lot of fun when watching it together with their teacher and me. They laughed and tried to teach me how to pronounce Polydron. They told me, "We are best friends" and "Polydron can be used for any purpose". I also followed up on the comment from the boy who asked their teacher to take a photo of what they had built. He told me that the picture was taken. Their teacher found an album that contained many pictures of a variety of things made with Polydron. The album was also available for parents to view.

The children, their teacher, and I - and probably the parents as well - seem to be amazed by this new material. At first glance - that is obvious in my transcription of the video - polydron comes forward as a material for the use of conscious, rational humans. After talking to the teacher and the children, I realised that the material can serve as a starting point for a range of different activities, and thereby as an actor. It is hard to know where the children as exploring actors ends and the material starts when it comes to what is made it appears to be an intra-activity. Polydron also intra-acts in a variety of practices in different children's play, in the choice of the teacher for what to record 
for our research, in the interview, and even, by the photos, extending to the families of the children. The exploring intra-activity seems to involve actors, including Polydron, children, photos, parents, teachers, understanding of good play, and me, in a network. All the actors made something happen - we made each other act.

\subsection{Polydron}

To understand why and how materials are intra-active actors in the practices of ECE, it is interesting to follow their history and the ontological meaning of the concept that labels the toys, that is, "Why is the toy Polydron called Polydron?" The website ${ }^{1}$ explains the concept of polydron as follows:

in geometry, a polyhedron (plural polyhedra or polyhedrons) is often defined as a three-dimensional object with flat, polygonal faces and straight edges. In this sense, it is a three-dimensional example of the more general structure called a polytope, which can have any number of dimensions. Cubes, prisms, and pyramids are examples of polyhedra.

A polyhedron surrounds a bounded volume in three-dimensional space; sometimes this interior volume is considered to be part of the polyhedron, sometimes only the surface is considered, and occasionally only the skeleton of edges. A polyhedron is said to be convex if its surface (comprising its faces, edges, and corners) does not intersect itself and the line segment joining any two points of the polyhedron is contained in the interior and surface. A regular polyhedron is one in which the faces are regular polygons that are all congruent (exactly alike) and assembled in the same way around each vertex (corner). More generally, in mathematics and other disciplines, the term polyhedron is used to refer to a variety of related constructs, some geometric and others purely algebraic or abstract.

From this text, I conclude that the toy Polydron might have inherited its name from the shape of the pieces, and from the interest in teaching children mathematics. From reading the text, I suggest that Polydron is intra-active to actors such as mathematics and education. The emphasis on mathematics in education made the act where children intra-act. In addition, traces of intra-activity can be observed from the description; it "does not intersect itself". Thus, it seems to be hard to separate the toy from actors such as mathematics, education, and humans. The way children use the material (intersect it) - and build shapes with the ability to join the polarity of the material - can be seen as intra-active when children explore this material in their play. Thereby, a space for agency among mathematics, education and humans is depicted. 
Space for agency when Polydron is present can also be traced from the web. ${ }^{2}$

Edward Harvey, who, in the 1970s, made these squares and triangles that were possible to pull together and separate again, did not initiate these squares for making a worldwide pedagogical toy. According to the website, Polydron is paving the way for children to learn mathematics, geometry, numbers, and density while they are building things, such as houses for play, and can be used both inside and outside. (Translated into English by the author)

Despite the text's presentation of the toy as interrelated to humans - as a tool for learning mathematics, geometry, numbers, and density - traces of intraaction can also be found, for example, the surprise of the inventor for the huge interest and expansion of the toy. This exemplifies Barad's (2003) description of the missing singular causality between intention, and how activities come into existence. Polydron as a non-human actor that, in an intra-activity with children's exploration, provides room for agency distributed among the children, Polydron, an understanding of education, mathematics, and good play.

\subsection{Materiality, Profit, Politics, Play, and Learning in ECE}

According to the sales representative of materials for ECE and schools, "basic toys,' such as cars, dolls, and equipment for play kitchens, are frequently sold to ECE institutions". These toys have a long history in ECE institutions. Despite this traditional approach to toys, Magnetic Polydron "has been the most popular toy in sales over the last five years", according to the seller. In line with the teacher's comments, he emphasises that "it can be used in multiple ways, and it conditions mathematical understanding". He said that "new toys for sale are most often connected to more than play". He continued, stating that "ECE institutions ask for materials that can be used in more formal learning activities, to meet the demands for more formal learning in ECE that is outlined in the Framework Plan for the content and task for Kindergartens". At his company's website, there is a specific link labelled learning, where many of these new products are presented. It is often material for concentration and construction. The sales representative emphasised, "Toys that stimulate mathematics are of special interest. In addition, products that stimulate activity and bodily movements, both indoors and outdoors, are also welcomed". Expected intra-activities involving play, learning, mathematics, and physical training are emerging. Moreover, economic profit emerges as an actor; what is offered and elaborated for sale has to provide income for the company that sells toys. The sales representative refers to the framework plan for ECE in Norway (UDIR, 2017), which 
has an emphasis on more structural learning. Therefore, the framework plan emerges as an actor, making it easier to sell toys that cover more than play (i.e. learning).

The group interview, as with the interview with the sales representative, turned out to be a discussion about play and learning, as it obviously would be about play, since I was bringing up questions about play. What is more interesting is that when we talked about play, learning became a part of the discussion. The relationship between play and learning was discussed whenever play was mentioned. Further, when asked about how to condition the play that was preferred by the teachers, a variety of conditions were mentioned, including: the competences and abilities of the staff, how to validate play because of the learning potential, real-life experiences, follow-up on children's interests - including media-based interests, architecture, how to split children into groups, time, play materials (such as Duplo blocks, equipment for playing doctor and so on), flexibility when it comes to tidying-up time, and room for a variety of types of play, including play that refers to violence.

The references to learning while discussing play was even touched upon when discussing how to condition play, and may indicate that an understanding of the need for more structural learning is emerging. The material aspect can also be traced by the teachers' references to architecture, Duplo blocks, and equipment for playing doctor. Hence, more than relationships and language are at the core, even though the conditions are mostly presented as a tool for play. In contrast, the teachers also mentioned the importance of "valuing the golden moments of eagerness, exploring, and the importance of conditioning children's possibilities to find new and unexpected answers". These utterances may be understood as resistance to the actor of more structural learning that is coming to the fore in their practices. In addition, actors such as politics emerge. They are traced from such comments as "children need time and space for play"; "their activities should not be limited to sitting down and learning"; "play is more than learning"; "we must avoid politicians that change ECE into an arena for pre-defined goals of learning". Politicians, the framework plan, structural learning, companies that sell with aims for economic profit, and golden moments emerge as actors in a network that constitutes practices in ECE.

When tracing emerging actors in my material in light of the outlined concepts of exploration, intra-activity, actors, and agency, several actors are found: Polydron, the position of play, the position of mathematics in education, the contemporary emphasis on more structural learning in ECE, the framework plan, economic profit, politics, children, teachers, parents, and me as the researcher. Therefore, instead of limiting agency to the involved children, a range 
of actors traced from a short video recording of an activity in the everyday life of ECE, can be traced. Thus, a relatively large space for agency is emerging.

The web presentations, the activity seen in the video, the teachers' comments on the activity, the children's comments, the discussions from the group interview, and the interview with the sales representative exemplify the lack of coherence between human intentions and the agency that emerges in the presented intra-activity. Pickering (1993) states that actors are continually coming into being, since performativity is temporarily emergent in practice. The contours of human and material actors are never fully known in advance; instead, they emerge in real time, in real practices. In this presentation of intra-activity in exploration, Polydron is easily radically changed or is continually coming into being, in different shapes. This intra-activity can turn into a variety of activities that can be both play and learning. Polydron, which is presented as a tool for learning mathematics, can even be involved in a game of princesses. The shapes and the multifactorial opportunities of the material pave the way for a continuum of practices to emerge. This challenges not only anthropocentric approaches to agency, but also the idea that humans can control practices.

My limited analysis of the children's exploration involving Polydron depicts how agency emerges. Materials, children, teachers, materialised heritage of play, materialised heritage of structural learning, the framework plan, mathematics, available materials from producers and sellers of material for ECE, teachers, children, and parents: all intra-act. This can serve as an example for agency as something other than something or someone has, toward agency as 'doing'/'being' in its intra-activity. Therefore, the conventional dichotomies of play and learning, humans and materials, and child-initiated and teacher-initiated activities are challenged. It is interesting that my aim of widening space for agency in ECE through destabilising children and humans, appears as a contrast to the heritage of the sociology of childhood that, in the first place, depicted children as something else than adults, but still in a position to influence, and thereby gave room for children's agency. Children came forward as beings and not only becomings. These steps have been important for children's position in society. Again, ambiguity and contradictions occur. That might indicate that the increasing complexity and ambiguity of childhood can be met by approaches that emphasise ambiguity, contradictions, and disruptions. To provide opportunities for children's lives, several actors can be challenged, especially when more than a child's ability to act forms room for agency. 


\section{Notes}

See http://web.newworldencyclopedia.org/entry/Polyhedron

2 See https://www.lekeakademiet.no/pl/Merker-Varemerker-Polydron_969o6.aspx

\section{References}

Barad, K. (2003). Posthumanist performativity: Toward an understanding of how matter comes to matter. Signs: Journal of Women in Culture and Society, 28(3), 801-831.

Barad, K. (2007). Meeting the universe halfway: Quantum physics and the entanglement of matter and meaning. Duke University Press.

Bornardo, L., \& Payne, R. (2012). Ambiguous agency: Critical perspectives on social interventions with children and youth in Africa. Children's Geographies, 10(4), 365-372.

Colegrove, K. S.-S. \& Adair, J. K. (2014). Countering deficit thinking: Agency, capabilities and the early learning experiences of children of Latina/o immigrants. Contemporary Issues in Early Childhood, 15(2), 122-132.

Deleuze, G., \& Guattari, F. (1988). A thousand plateaus: Capitalism and schizophrenia II. Althlone.

Esser, F., Baader, M. S., Betz, T., \& Hungerland, B. (2016). Reconceptualising agency and childhood an introduction. In F. Esser, S. Meike, T. B. Betz, \& B. Hungerland (Eds.), Reconceptualising agency and childhood. New perspectives in childhood studies (pp. 1-16). Routledge.

Hammersley, M., \& Atkinson, P. (2007). Ethnography: Principles in practice. Routledge.

Hultman, K., \& Taguchi, H. L. (2010). Challenging anthropocentric analysis of visual data: A relational materialist methodological approach to educational research. International Journal of Qualitative Studies in Education, 23(5), 525-542.

Jackson, A. Y. (2013). Posthumanist data analysis of mangling practices. International Journal of Qualitative Studies in Education, 26(6), 741-748.

James, A. (2009). Agency. In J. Qvortrup, W. A. Corsaro, \& M.-S. Honig (Eds.), The Palgrave handbook of childhood studies (pp. 34-45). Palgrave.

Kummen, K. (2014). Making space for disruption in the education of early childhood educators (Ph.D. thesis). University of Victoria.

Lafton, T. (2015). Digital literacy practices and pedagogical moments: Human and nonhuman intertwining in early childhood education. Contemporary Issues in Early Childhood, $16(2), 142-152$.

Latour, B. (1993). We have never been modern. Harvester/Wheatsheaf.

Latour, B. (2005). Reassembling the social: An introduction to actor-network-theory. Oxford University Press. 
Lee, N. (2001). Childhood and society: Growing up in an age of uncertainty. Open University Press.

Leirpoll, B. (2015). En åpenhet for hendelser som kommer - om å plugge teori inn i og dermed improvisasjonens mulighet for andre innganger til - barnehagelærerens etiske praksis. In A. M. Ottestad \& A. B. Reinertsen (Eds.), Metodefestival og øyeblikksrealisme - eksperimenterende kvalitative forskningspassasjer (pp. 103-132). Fagbokforlaget.

Leonard, M. (2016). The sociology of children, childhood and generation. Sage.

Mizen, P., \& Ofosu-Kusi, Y. (2013). Agency as vulnerability: Accounting for children's movement to the streets of Accra. The Sociological Review, 61(2), 363-382.

Myhre, C. O., Myrvold, H. B., Joramo, U.-W., \& Thoresen, M. (2017). Stumbling into the 'kitchen island': becoming through intra-actions with objects and theories. Contemporary Issues in Early Childhood, 18(3), 308-321.

Nsamenang, A. B. (2008). Agency in early childhood learning and development in Cameroon. Contemporary Issues in Early Childhood, 9(3), 211-223.

Payne, R. (2012). Extraordinary 'survivors' or 'ordinary lives'? Embracing 'everyday agency' in social interventions with child-headed households in Zambia. Children's Geographies, 10(4), 399-411.

Pickering, A. (1993). The mangle of practice: Agency and emergence in the sociology of Science. American journal of sociology, 99(3), 559-589.

Prout, A. (2011). Taking a step away from modernity: Reconsidering the new sociology of Childhood. Global Studies of childhood, 1(1), 4-14.

Sandvik, N. (2015). Posthumanistiske perspektiver. Bidrag til 'barnehageforskning'. In A. M. Ottestad \& A. B. Reinertsen (Eds.), Metodefestival og øyeblikksrealisme eksperimenterende kvalitative forskningspassasjer (pp. 45-62). Fagbokforlaget.

Spyrou, S. (2018). What kind of agency for children? In S. Spyrou (Ed.), Disclosing childhood, for a critical childhood studies (pp. 117-156). Palgrave Macmillan.

Srinivasan, P. (2018). Pookey, poory, power: An actoric powerformance. Contemporary Issues in Early Childhood. https://doi.org/10.1177/1463949118759979

UDIR Norwegian Directorate for Education and Training. (2017). Framework Plan for the content and tasks of kindergartens. Norwegian Directorate for Education and Training.

United Nations. (1989). United Nations Convention on the Rights on the Child. https://downloads.unicef.org.uk/wp-content/uploads/2010/05/ UNCRC_united_nations_convention_on_the_rights_of_the_child.pdf? ga $=2.2595^{82415} \cdot 454887985.1587459175-44770236.1585716747$

Valentine, K. (2011). Accounting for agency. Children and Society, 25(5), 266-278. 